\title{
Diagnostic Value of Susceptibility Weighted Imaging in Sinus Venous Thrombosis
}

\author{
Bagheri A. ${ }^{1} M S c$, Faeghi F.* PhD, Rabbani M. ${ }^{2} P h D$, Jabbari K. ${ }^{3} P h D$
}

\author{
*Radiology Technology Department, Allied Medical Sciences School, Shahid Beheshti University of Medical \\ Sciences, Tehran, Iran \\ ${ }^{1}$ International Branch, Shahid Beheshti University of Medical Sciences, Tehran, Iran \\ ${ }^{2}$ Radiology Department, Medicine School, Isfahan University of Medical Sciences, Isfahan, Iran \\ ${ }^{3}$ Medical Physics \& Engineering Department, Medicine School, Isfahan University of Medical Sciences, Isfahan, \\ Iran
}

\begin{abstract}
Aims: Magnetic resonance venography based on susceptibility weighted imaging (SWI) utilizes deoxygenated hemoglobin in veins as an intrinsic contrast medium. Magnetic susceptibility difference between deoxygenated hemoglobin, oxygenated hemoglobin and parenchyma lead to an excellent venous contrast. The purpose of this study was to evaluate the different magnetic resonance imaging sequences and susceptibility weighted imaging in the visualization of sinus venous thrombosis.

Materials \& Methods: This cross-sectional study was performed in Shafa Medical Imaging Center in Isfahan City, Iran, from August 2013 to September 2014 and 12 patients with sinus venous thrombosis were analyzed using MRI, SWI, and Phase contrast-magnetic resonance venography (PC-MRV).

Findings: In all patients, sub-acute superior sagittal sinus, transverse and sigmoid sinuses thrombosis was most successfully detected during the susceptibility weighted imaging. In only one case, the sub-acute left transverse and sigmoid sinuses and left jugular vein of thrombosis was discernible with $\mathrm{T} 1 \mathrm{~W}$. In 6 patients, sinus venous thrombosis was discernible with $\mathrm{T} 2 \mathrm{~W}$ in the sub-acute stage. PC-MRV showed the acute and sub-acute sinus venous thrombosis in all patients.

Conclusion: Susceptibility weighted imaging has a high diagnostic value for detecting sub-acute superior sagittal sinus, transverse and sigmoid sinuses thrombosis.
\end{abstract}

\section{Keywords}

Susceptibility Weighted Imaging [Not In MeSH];

Magnetic Resonance Imaging [http://www.ncbi.nlm.nih.gov/mesh/68008279];

Venous Thrombosis [http://www.ncbi.nlm.nih.gov/mesh/68020246] 


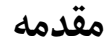

ترومبوز سينوسهاى وريدى مغز، بيمارى نادرى است كه از هر

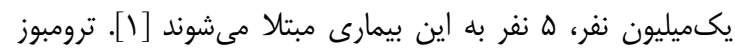

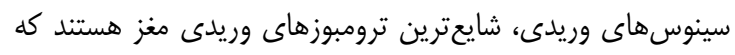
دالت بر انسداد ترومبوتيك يك يا ئند

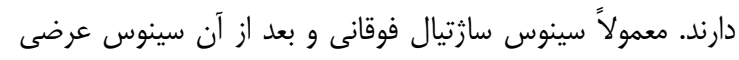

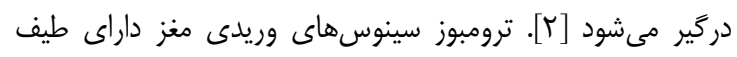

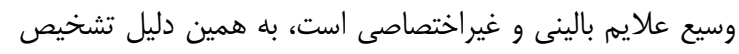

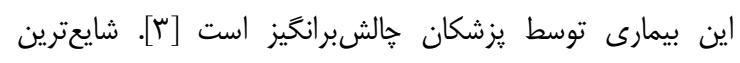

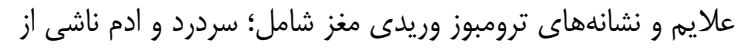

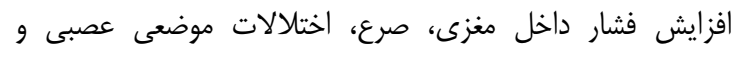
هوشيارى تغيير يافته است. اين علايم (سردرد، تشنج، افزايش فئار إنار

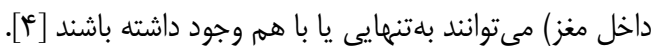

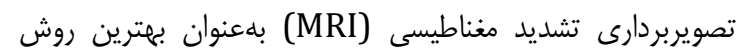

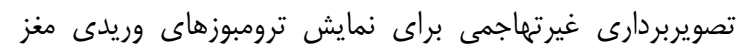

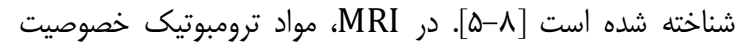

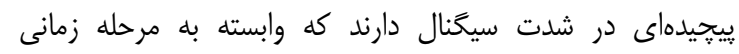

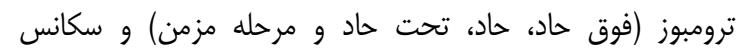

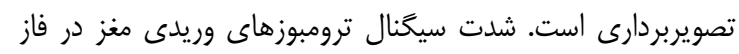
حاد يعنى طى ه روز اول از شروع علايم در تصاوير وزنى تصنى

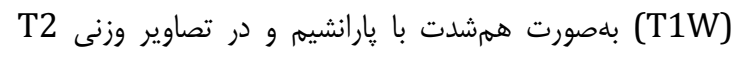

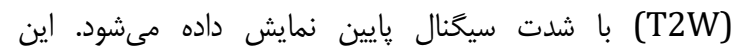

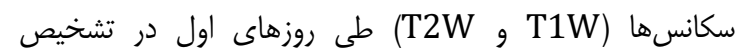
ترومبوزهاى وريدى مغز حساسيت كمترى نشان مى دهنائد، بنابر اين

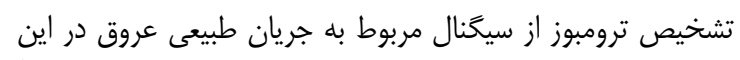

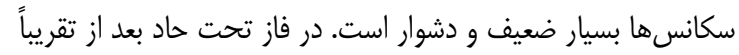

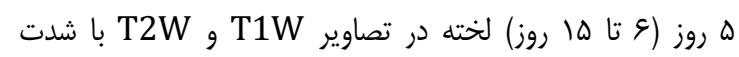
سيخنال بالا نمايان مى شود [ب].

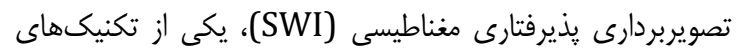

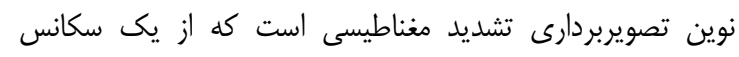

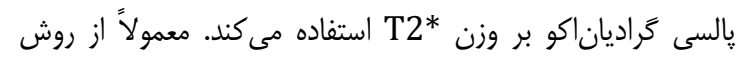

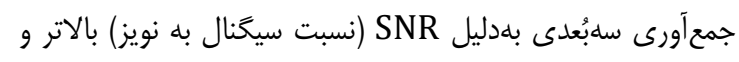

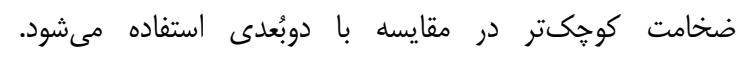

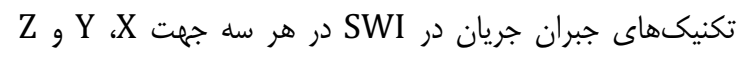

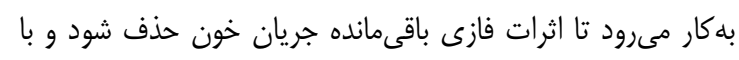

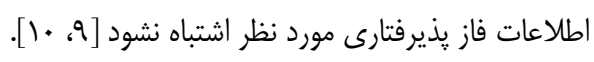

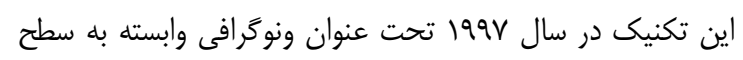

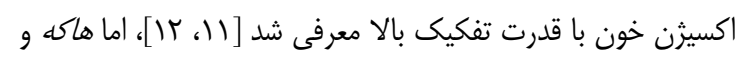

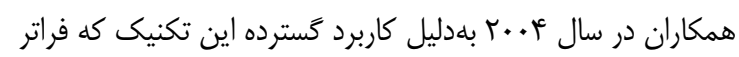

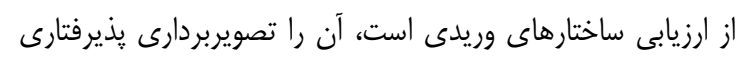

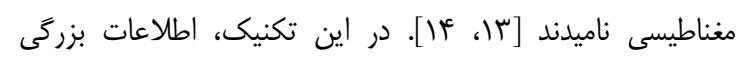
سيكنال (مكنيتود) و اطلاعات فازى با همديكر تركيب مىشوند.

\section{ارزش تشخيصى تصويربردارى يذيرفتارى مغناطيسى در ترومبوز سينوس لهاى وريدى}

اكرم باقرى MSc

شعبه بينالملل، دانشخاه علوم يزشكى شهيد بهشتى، تهران، ايران

PhD "فيبرز فائقى

كروه تكنولوزى راديولوزى، دانشكده بيريرايزشكى، دانشكاه علوم يزشكى شهيد بهشتى، تهران، ايران

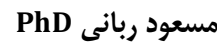

كروه راديولوزى، دانشكده يزشكى، دانشخاه علوم يزشكى اصفهان، اصفهان، ايران

كيوان جبارى PhD

كَروه فيزيك يزشكى، دانشكده يزشكى، دانشاء علوم يزشكى اصفهان، اصفهان، ايران

جكيده

اهداف: ونوكًافى تشديد مغناطيسى براساس تصويربردارى يذيرفتارى

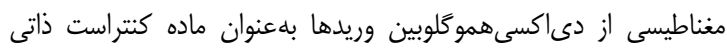

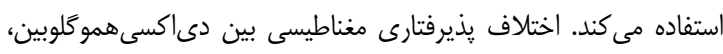

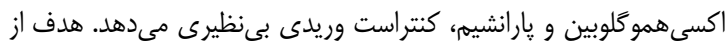

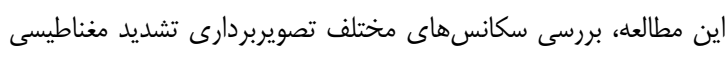

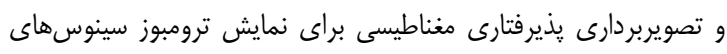

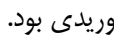

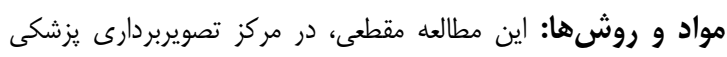

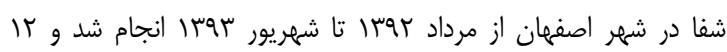

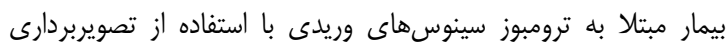

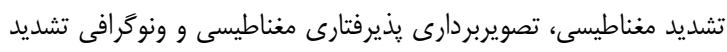
مغناطيسى با كتنراست فازى آناليز شدند.

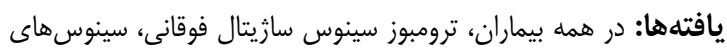

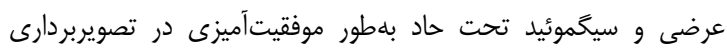

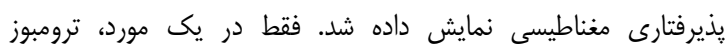

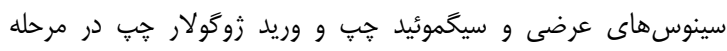

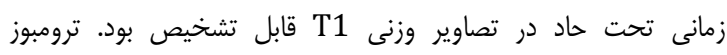

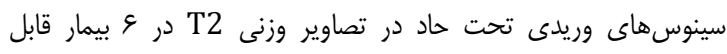

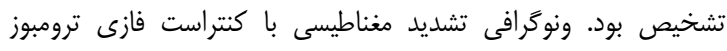

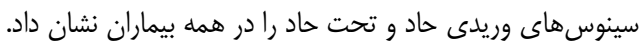

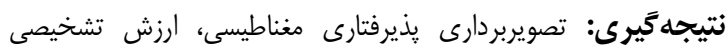

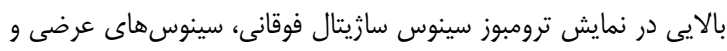
سيخموئيد تحت حاد دارد.

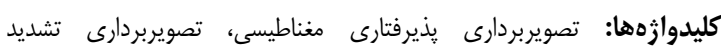
معناطيسى، ترومبوز سينوسهاى وريدى تصري

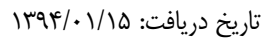

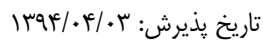

"نويسنده مسئول: f.faeghi@yahoo.com

دوره آس، شماره سا، هاييز

فصل فامه افق دانش 
ارزش تشخيصى تصويربردارى يذيرفتارى مغناطيسى در ترومبوز سينوسهاى وريدى 191

T2W(FSE)

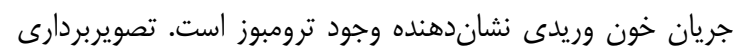

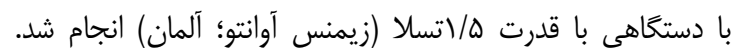

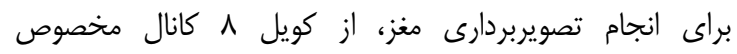

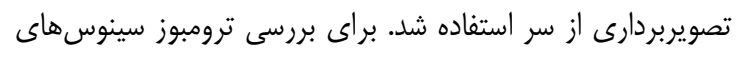
وريدى مغز از تعدادى سكانس به شرح زير استفاده شد:

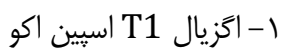

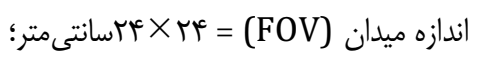

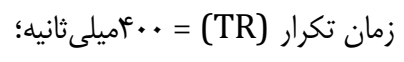
زمان اكو (TE) = أميلى ثانيه؛

ضخامت مقطع = هميلى متر

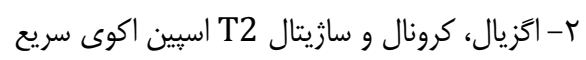

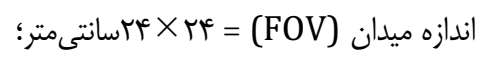

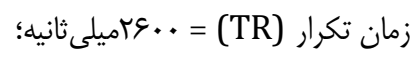

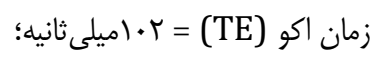
ضخامت مقطع = هميلى متر

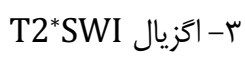

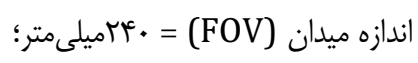

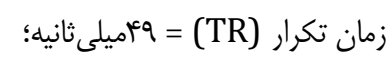
زمان اكو (TE) = • •أميلى ثانيه؛ ضخامت مقطع = بميلىمتر زاويه انحراف = هادرجه؛

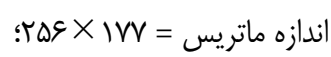

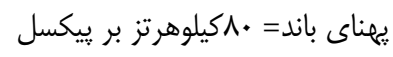
PC-MRV -r

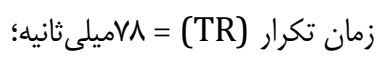
زمان اكو (TE) = • • اميلى ثانيه؛

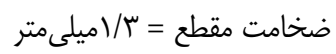
زاويه انحراف = هادرجه؛

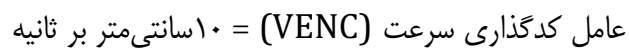

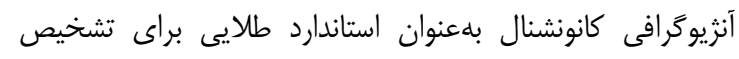

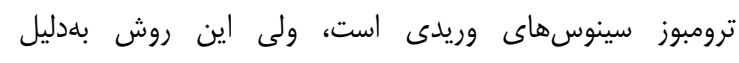
تهاجمىبودن، در يثوهش مورد استفاده قرار نكَرفت. PC-MRV

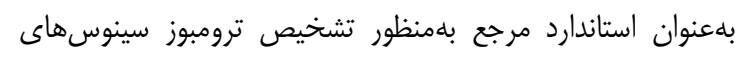
وريدى مغز استفاده شد. قابليت نمايش ترومبوزهاى وريدى در سكانس هاى مختلف MRI SWI و PC-MRV

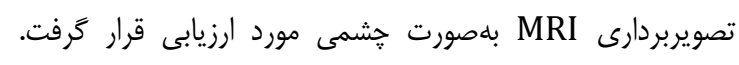

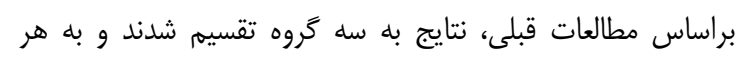

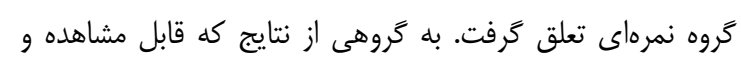

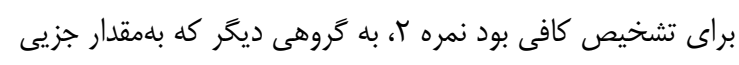

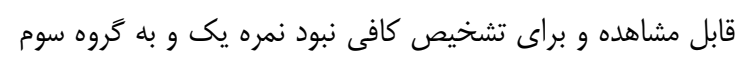

تصاوير فازى شامل تغييرات فازى با فركانس فضايى بايين است كه

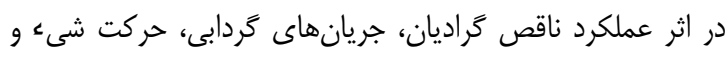

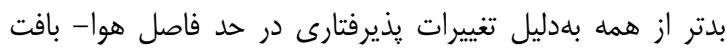

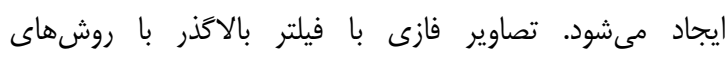

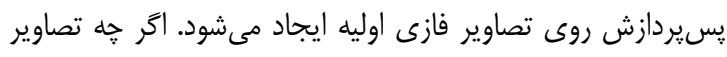

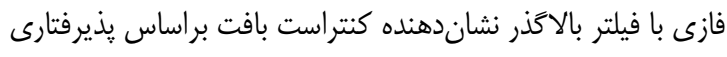

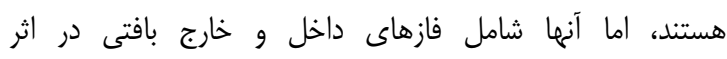

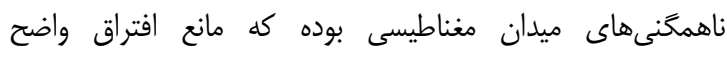

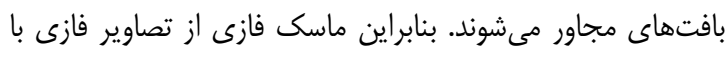

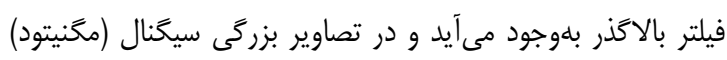

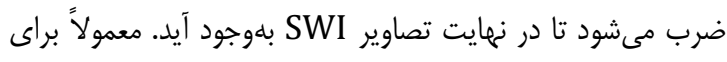

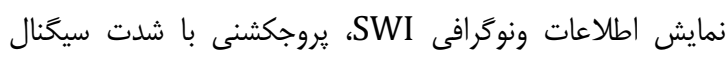

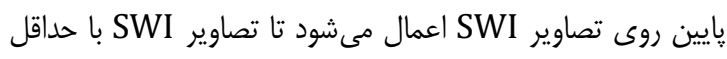

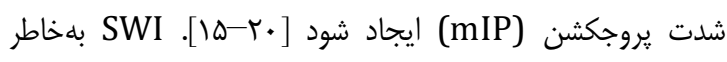

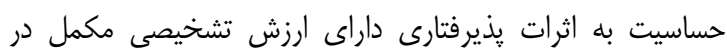

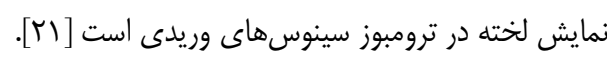

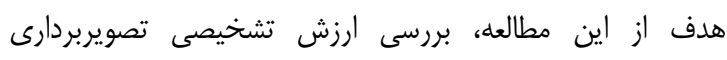

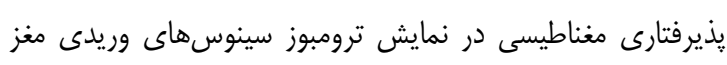

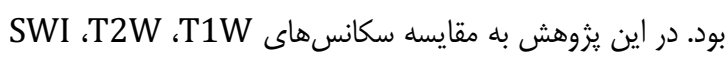

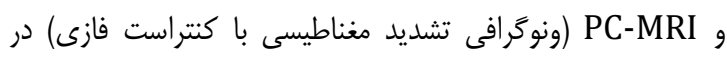
تشخيص ترومبوز سينوس هاى وريدى يرداخته شد.

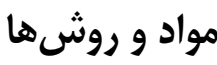

اين مطالعه مقطعى، در مركز تصويربردارى شفا در شهر اصفهان إنهان از

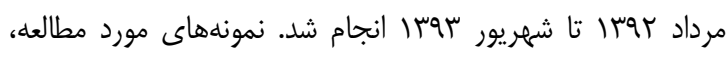

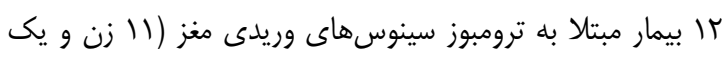

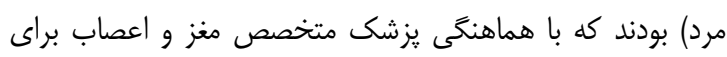

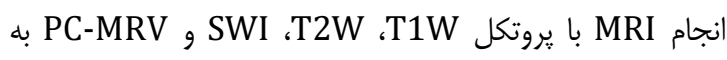

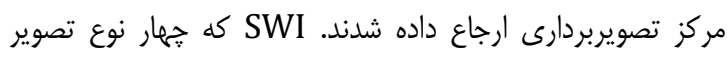

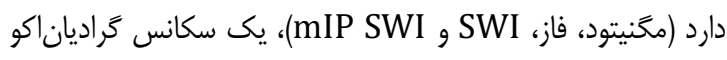

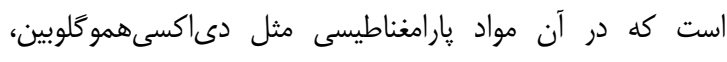

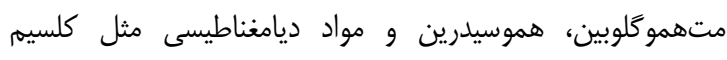

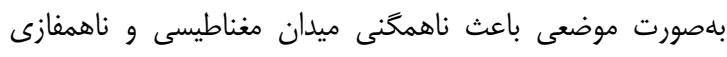

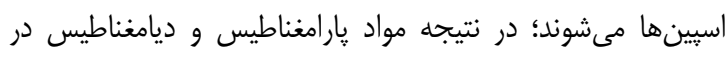
تصاوير MIP SWI ،WI) SWI و مخَنيتود) با شدت سيكنال

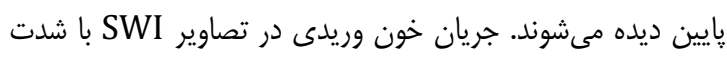

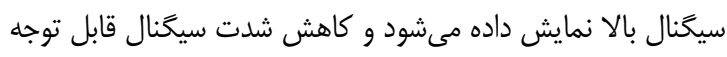

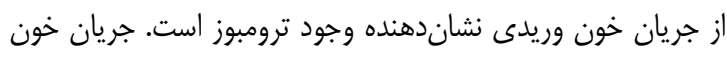

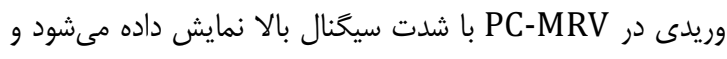

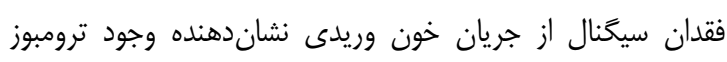

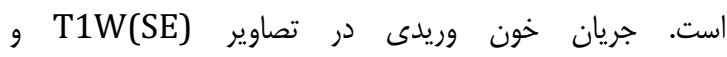


سازيتال تحتانى، س نفر مبتلا به ترومبوز سينوس عرضى راست، س

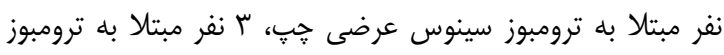
سينوس سيخموئيد راست، گ نفر مبتلا به ترومبوز سينوس سيخموئيد هُ زوگَلار جֶٍ و يك نفر مبتلا به ترومبوز سينوس مستقيم و وريد

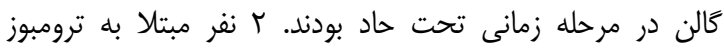
سينوس عرضى جֶٍ و يك نفر مبتلا به ترومبوز سيگموئيد جֶٍ در مرحله زمانى حاد بودند. نتايج مطالعه نشان درئ داد كه به ترومبوز سينوسهاى وريدى، در سينوس سازيتال فوقانى با فراوانى $\&$ نفر

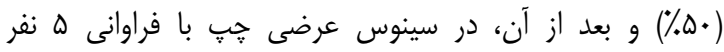

شايع بود. (1/V)

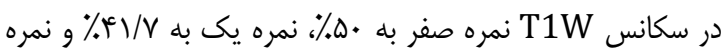

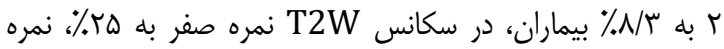

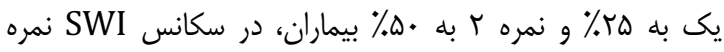

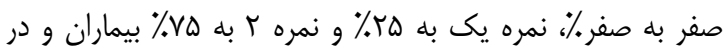

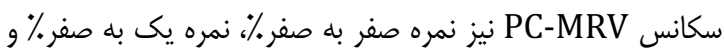

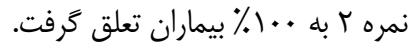
ترومبوز سينوسهاى سازيتال فوقانى، عرضى و سيخموئيد در مرحله زمانى تحت حاد قابل تشخيص بودند (شكلهاى ا و عام). ترومبوز

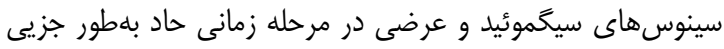
مشاهده شدند، ولى براى تشخيص كافى نبودند (شكل سار). ترومبوز

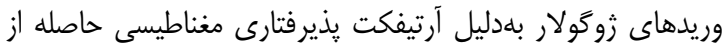

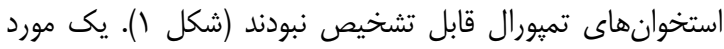

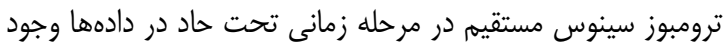
داشت كه قابل تشخيص بود. دو مورد ترومبوز سينوس ساريتال تحتانى در مرحله زمانى تحت حاد در دادهها وجود داشت كه قابل

$$
\text { تشخيص بودند (شكل أ). }
$$

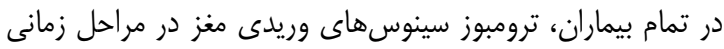

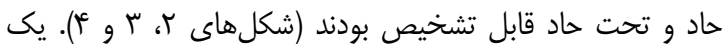

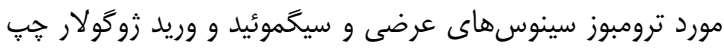

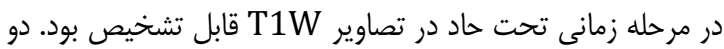
مورد ترومبوز سينوس سازيتال فوقانى و يك مورد ترومبوز سينوس

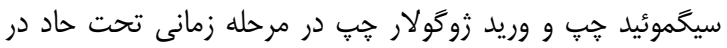
تصاوير T2W بdطور جزيى مشاهده شد، ولى براى تشخيص كافى نبود. در بقيه موارد ترومبوز سينوس هاى وريدى در مرحله زمانى

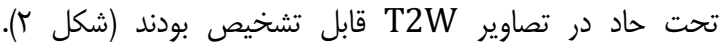
ترومبوز سينوس مستقيم در مرحله زمانى تحت حاد در تصاوير قابل تشخيص بود. ترومبوز سينوسهاى سيخموئيد و عرضى در مرحله زمانى حاد در تصاوير T1W و T2W قابل ترديل تشخيص نبودند (شكل r). ترومبوز سينوس سازيتال تحتانى در

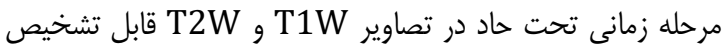

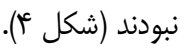

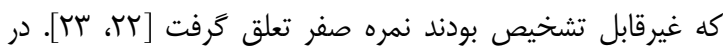

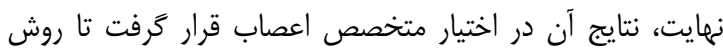
صحيح درمان را براى بيماران فوق مشخص كند.

يافتهها

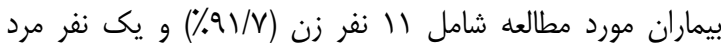

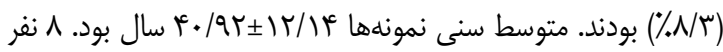

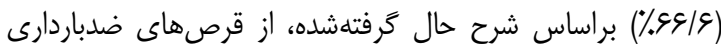

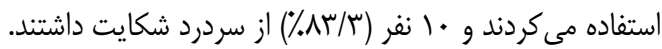
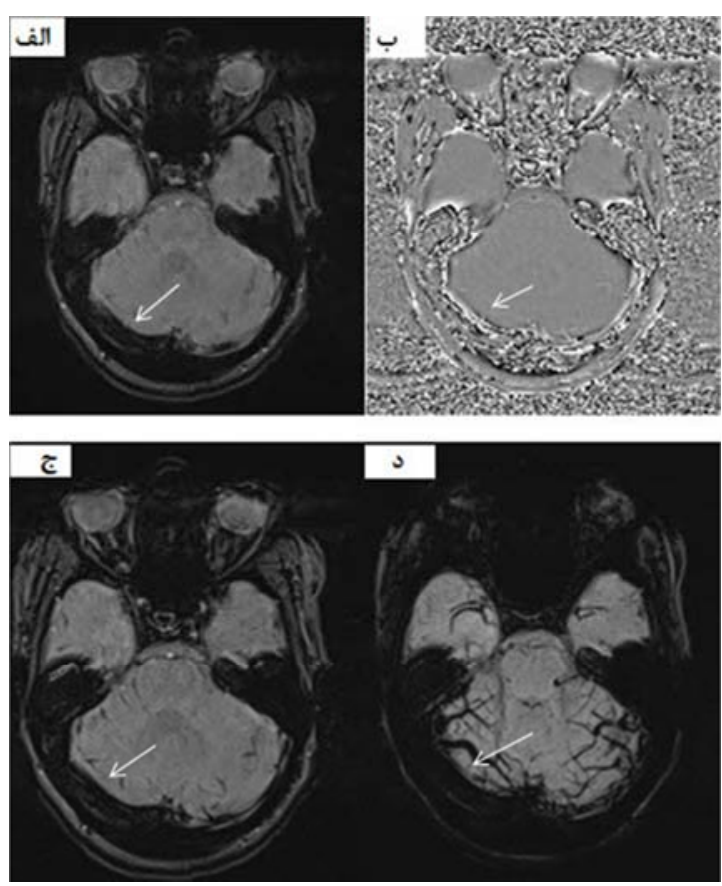

شكل () زن آسالهاى (بيمار اول) با علايم سردرد، سرَيجه، حالت تهوع و

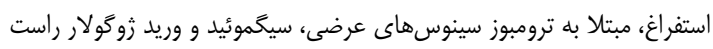

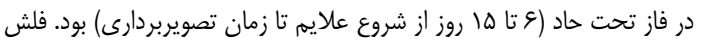

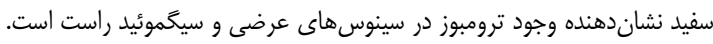

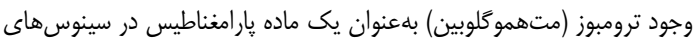

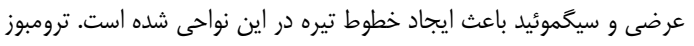

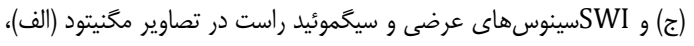

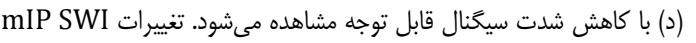

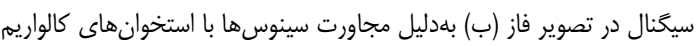

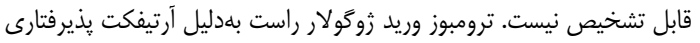

مغناطيسى حاصله از استخوانهاى تميورال قابل تشخيص نيست.

از rا بيمار مبتلا به ترومبوز سينوسهاى وريدى مغزى، س نفر

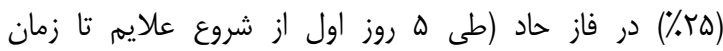

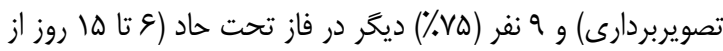

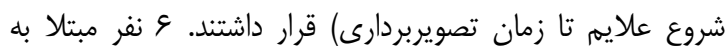
ترومبوز سينوس سازيتال فوقانى، r نفر مبتلا به ترومبوز سينوس 


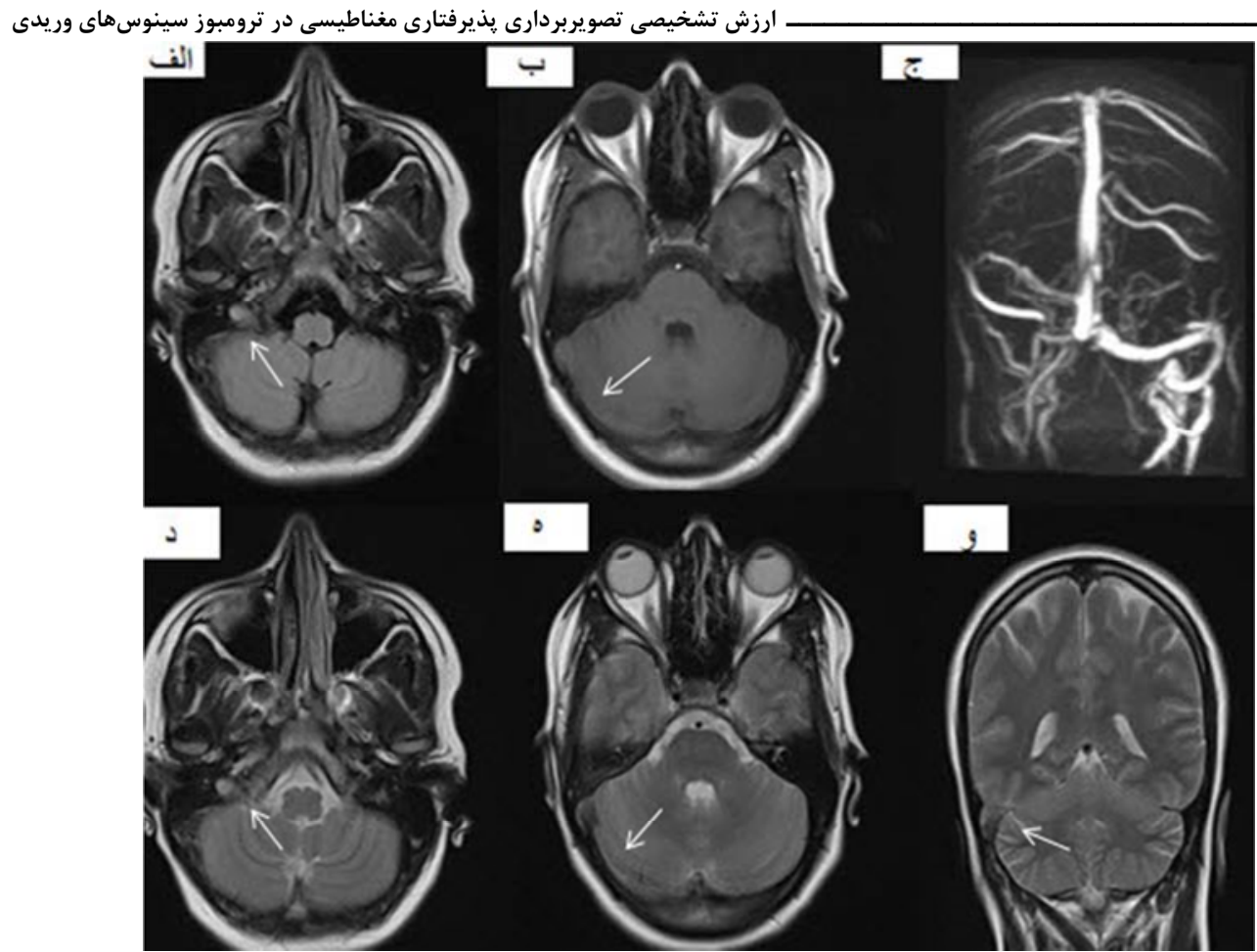

شكل r) بررسى سكانس هاى روتين PC-MRV و MRI در بيمار اول. ترومبوز وريد زوكولار داخلى راست در تصوير T1W (الف) و T2W (د) داراى شدت سيكنال

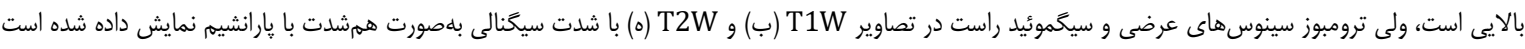

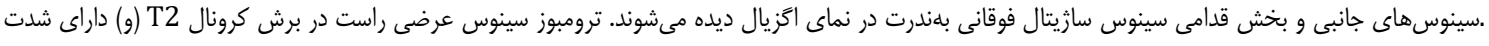

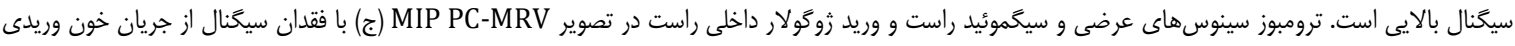
مشاهده مى شود.

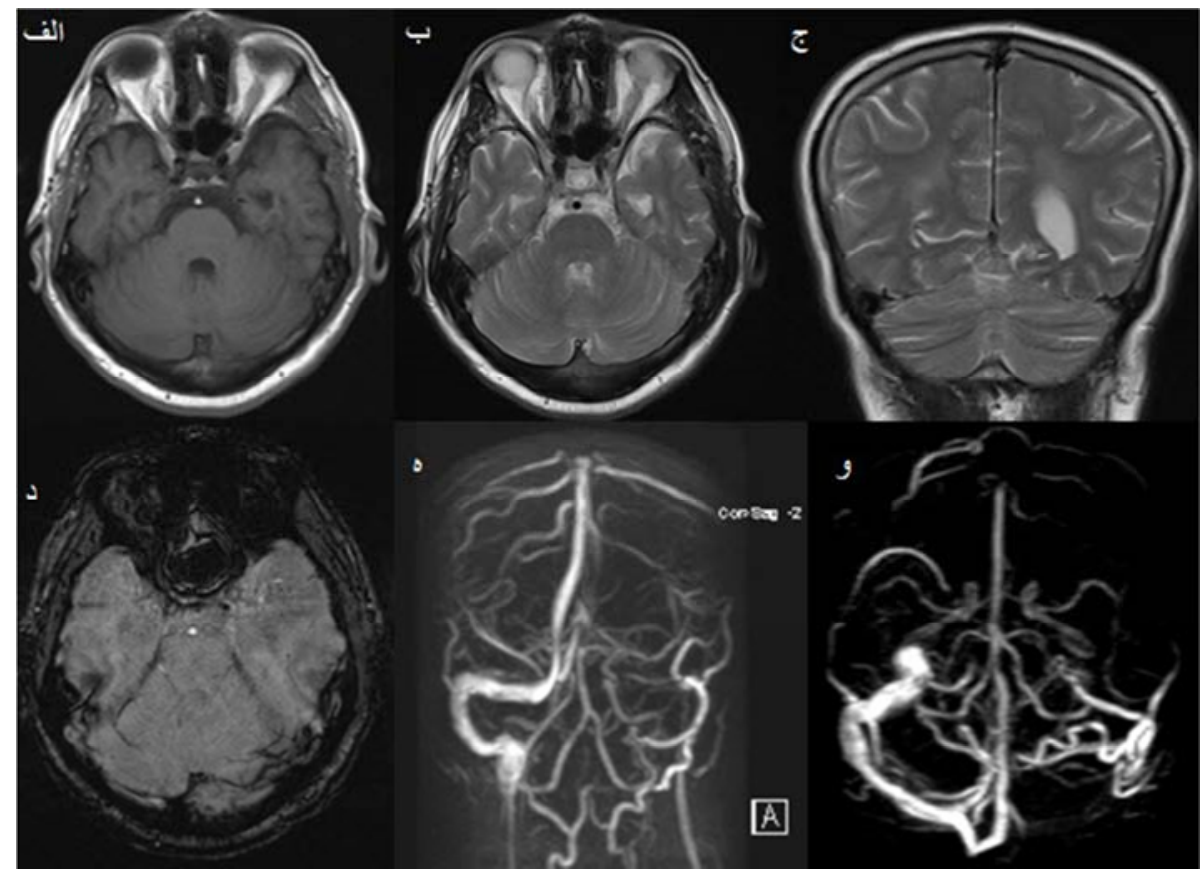

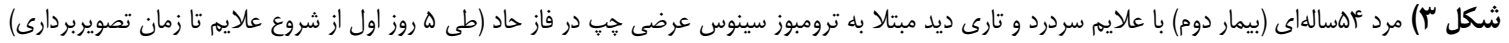

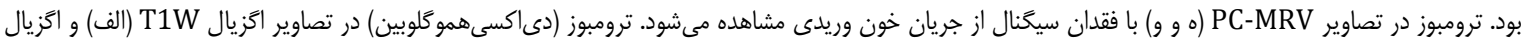

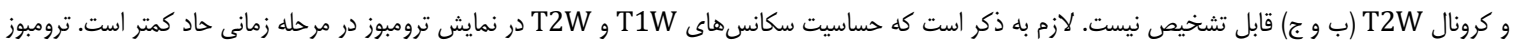

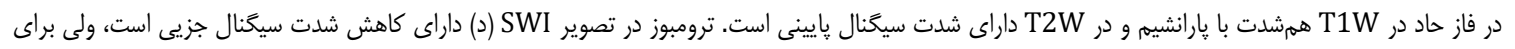

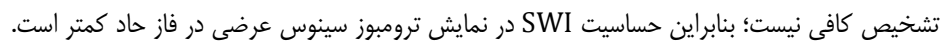




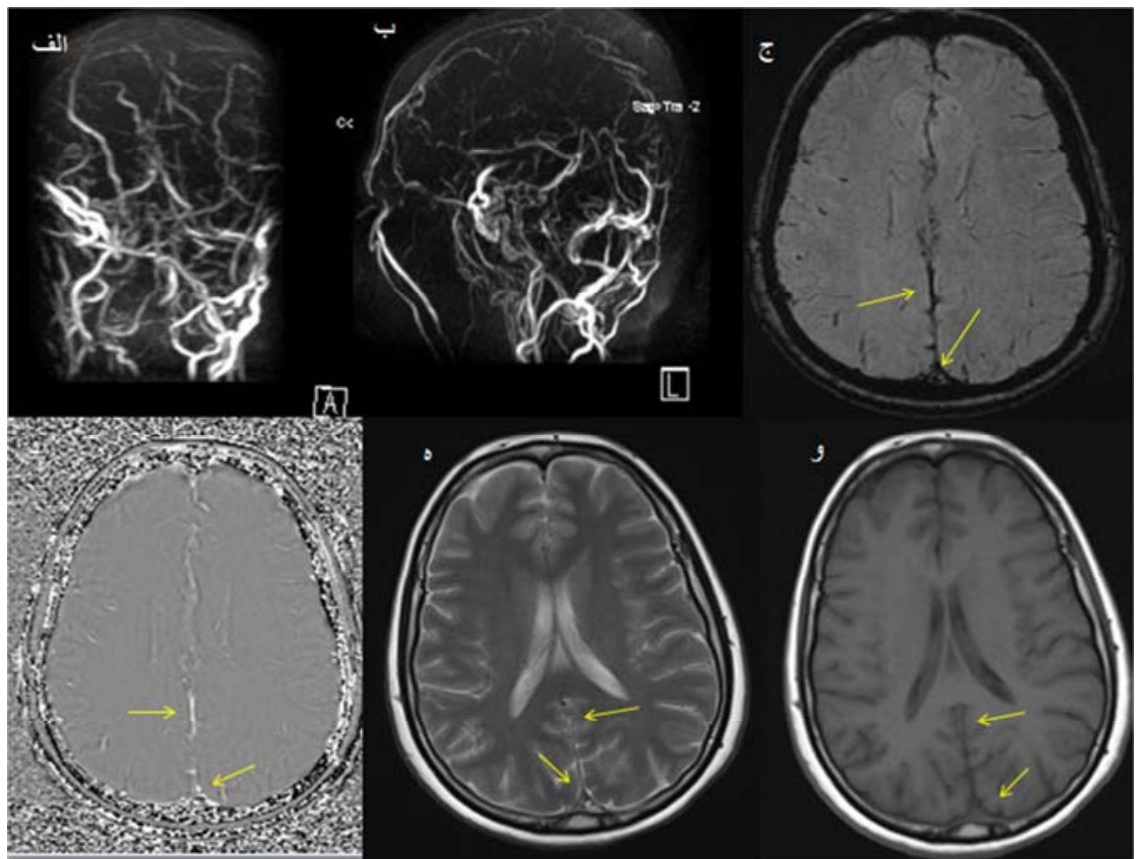

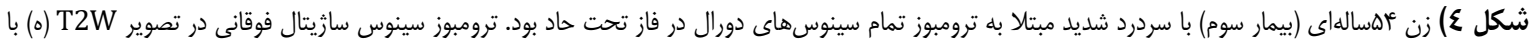

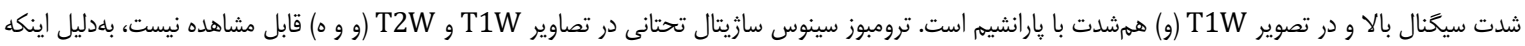

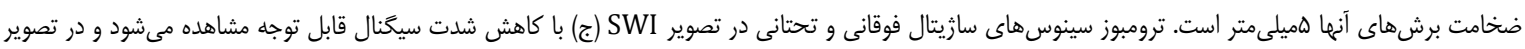

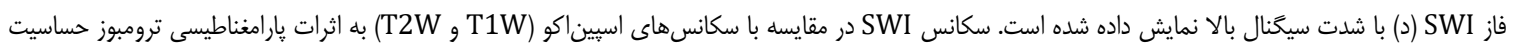

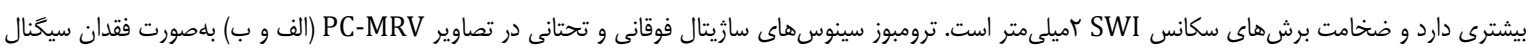
از جريان خون وريدى سينوس ها مشاهده مى شود.

تحقيقات موجود درباره تشخيص ترومبوز سينوسهاى وريدى

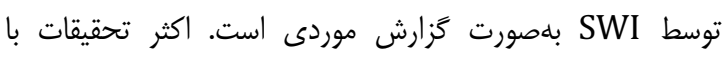

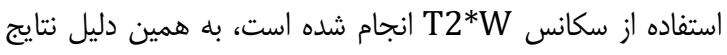
SWI

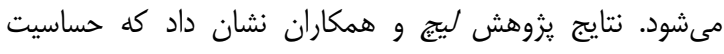

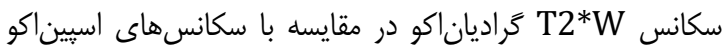

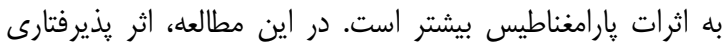

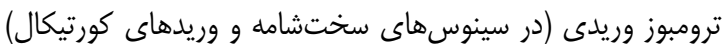

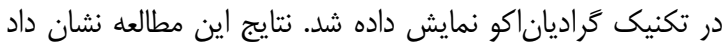

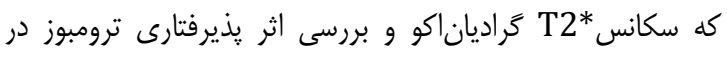

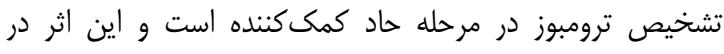

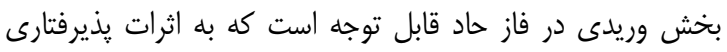

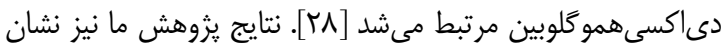

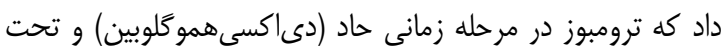

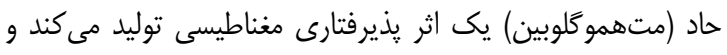

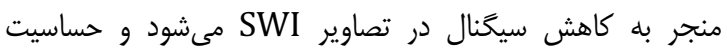
SWI

$$
\text { اثرات يارامغناطيس بيشتر است. }
$$

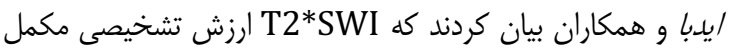

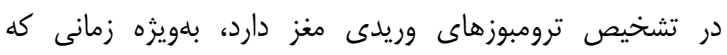

\section{بحث}

ترومبوز سينوسهاى وريدى، كمياب و از عوامل مهم استروى

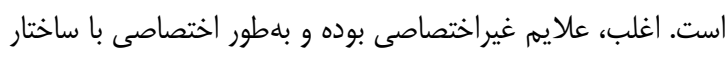

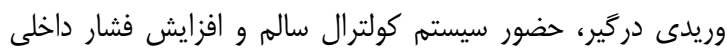

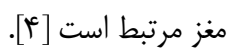
در تحقيقى كه توسط بوسر و كراسارد انجام شد، شيوع ترومبوز در

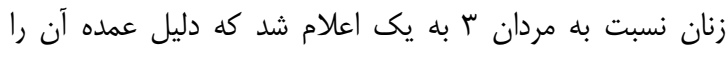

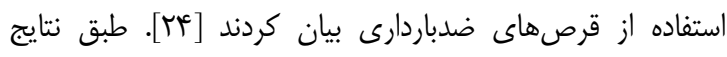

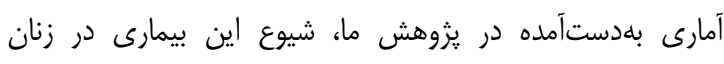

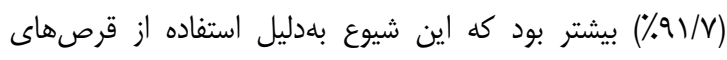

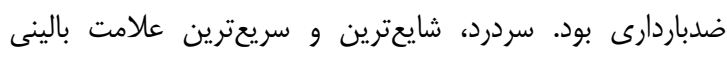

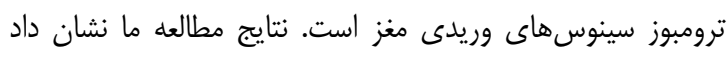

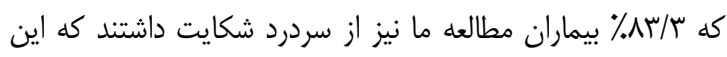

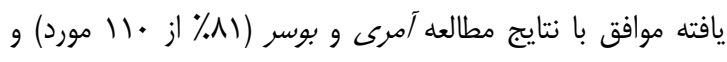

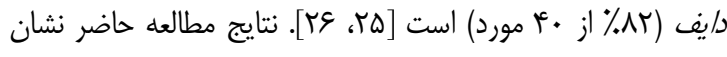

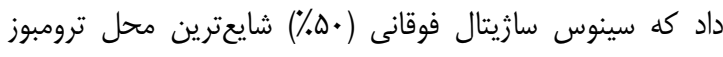

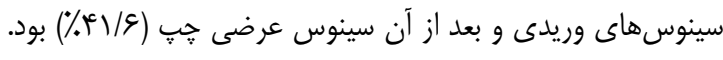

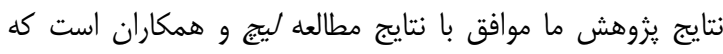

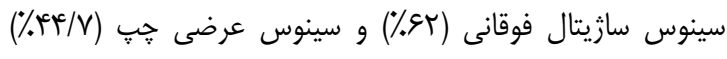

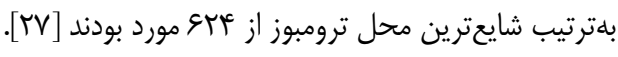

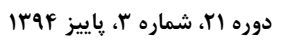
فصل نامه افق دانش 
19ه ارزش تشخيصى تصويربردارى يذيرفتارى مغناطيسى در ترومبوز سينوسهاى وريدى

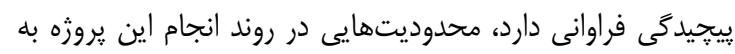

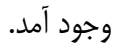

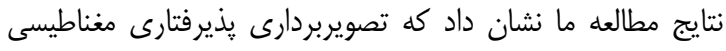
ارزش تشخيصى بالايى در نمايش ترومبوز سينوس هاى سازيتال

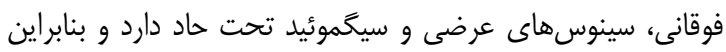

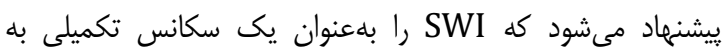
سكانسهاى روتين MRI و MRV در تشخيص ترومبوز سينوسهاى وريدى اضافه كنيم. همجنين سكانس PC-MRV در نمايش ترومبوز سينوسهاى وريدى در مراحل زمانى حاد و تحت

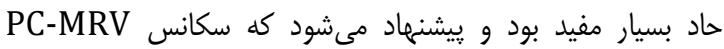

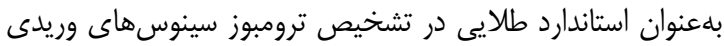

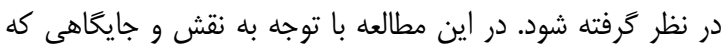
تكنيى SWI در تشخيص ترومبوز سينوس هاى وريدى در مغز درد

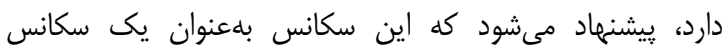
تحقيقاتى و كاربردى در مراكز استروى و بيمارىهاى عروقى مغزى ينسي

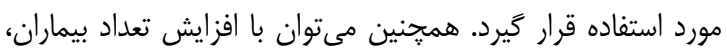

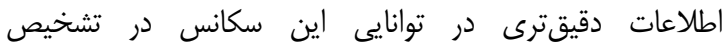
سينوسهاى وريدى مغزى بلهور دستهبندىشده بلددست آورد.

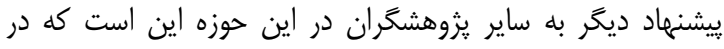

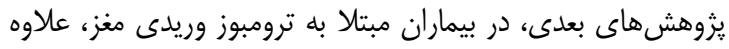
بر سكانس هاى روتين MRI و MRI و كرادياناكو كانونشنال استفاده كنند و يافته ئهاى بلهدستآمده از سكانس SWI با S2*W كرادياناكو كانونشنال مقايسه شود تا بتوان به نتايج بهتر و دقيقترى دست يافت.

\section{نتيجه كَيرى}

تصويربردارى يذيرفتارى مغناطيسى، ارزش تشخيصى بالايى در

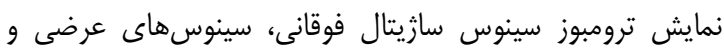
سيخموئيد تحت حاد دارد.

تشكر و قدردانى: اين مقاله بركرفته از بايان نامه كارشناسىارشد

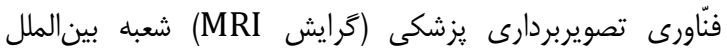

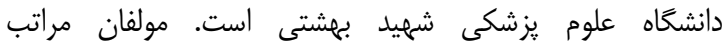

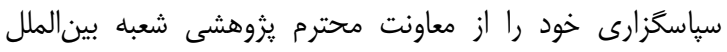

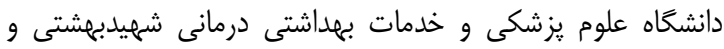
مركز تصويربردارى شفا در اصفهان ابراز مى دارند. تاييديه اخلاقى: يثوهش حاضر در شعبه بينالملل دانشگاه علوم يزشكى و خدمات بهداشتى درمانى شهيد بهشتى به شماره

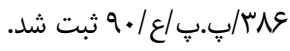

تعارض منافع: تعارض منافعى وجود نداشته است. منابع مالى: منابع مالى اين طرح ثروهشى توسط نويسنده تامين شده است.
حساسيت سكانسهاى ديخر (T1W و T2W و FLAIR) كمتر است. نتايج مطالعه ما نيز نشان داد كه SWI در مقايسه با T1W و

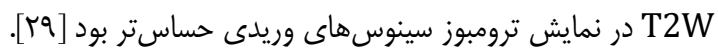

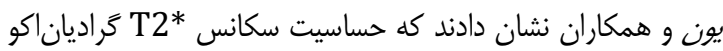
در مقايسه با سكانسهاى T1W، و و T2W يارامغناطيس بيشتر است و سكانسهايى مانند فلاير و T1W با تزريق در نمايش ترومبوز در فاز حاد مفيد نيستند. همجنين آنيا آنها

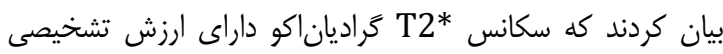
بالايى در تشخيص اوليه ترومبوز سينوسهاى وريدى است و تاثير

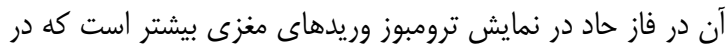

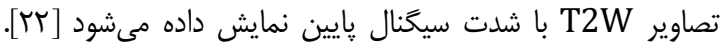

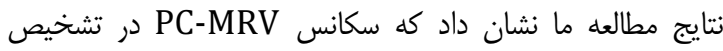
ترومبوز سينوسهاى وريدى در مراحل حاد و تحت حاد بسيار مفيد

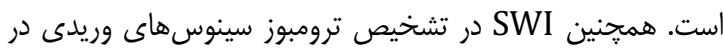
مرحله تحت حاد مفيد است، ولى در مرحله حاد مفيد نيست.

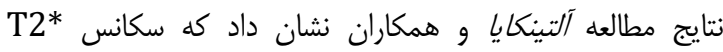
كرادياناكو ارزش تشخيصى بالايى در نمايش ترومبوز سينوس سازيتال فوقانى، وريدهاى عمقى و وريدهاى كورتيكال در مرحله حاد و تحت حاد دارد. همجنين بيان كردند كه اين سكانس در نمايش ترومبوز در فاز مزمن ارزش تشخيصى ندارد. اين اختلاف با دان اثر يذيرفتارى فرأوردهاى ناشى از شكست همو كلوبين در فاز حاد و تحت حاد مرتبط است [سr]. ترومبوز سينوسهاى سيخموئيد و عرضى در سكانس T2* عراديان بهدليل آرتيفكت يذيرفتارى قاعده

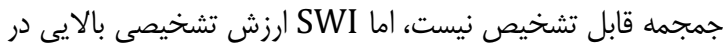
تشخيص ترومبوز سينوس هاى سيخموئيد و عرضى در فاز تحت حاد

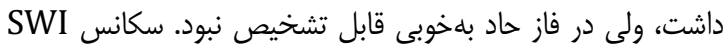
در مقايسه با سكانس T2*W در نمايش تعداد و انداره ضايعات نواحى خلفى مغز بالاتر است، زيرا روشهاى يسيردازش روى لهاي

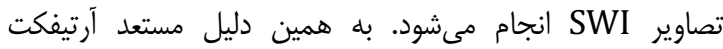

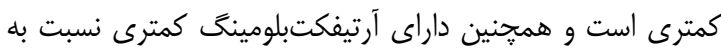
T2*W

از محدوديتهاى اين يثوهش مىتوان به موارد زير اشاره كرد:

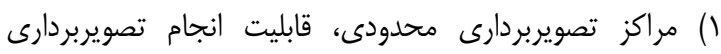
يذيرفتارى مغناطيسى را دارند و بdدليل مشكلات مراكز و همجنين تعدد بيماران، تعداد خيلى كمى از مراكز موجود به استفاده از اين

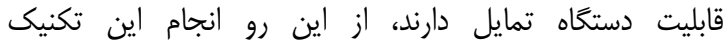
تصويربردارى بسيار محدود شده است.

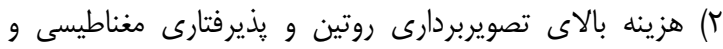
همجنين كمياببودن نوع بيمارى، در كاهش تعداد بئن بيماران اين مطالعه نقش اساسى داشته است.

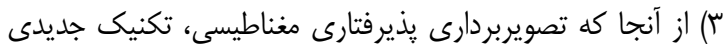

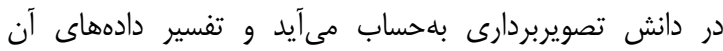


Susceptibility-weighted imaging: Technical aspects and clinical applications, part 1. AJNR Am J Neuroradiol. 2009;30(1):19-30.

17- Nair JR, Van Hecke W, De Belder F, Venstermans C, van den Hauwe L, Van Goethem J, et al. High-resolution susceptibility-weighted imaging at $3 \mathrm{~T}$ with a 32-channel head coil: Technique and clinical applications. AJR Am J Roentgenol. 2010;195(4):1007-14.

18- Robinson RJ, Bhuta S. Susceptibility-weighted imaging of the brain: current utility and potential applications. J Neuroimaging. 2011;21(4):189-204.

19- Meoded A1, Poretti A, Northington FJ, Tekes A, Intrapiromkul J, Huisman TA. Susceptibility weighted imaging of the neonatal brain. Clin Radiol. 2012;67(8):793-801.

20- Zee CS. Yan Ch. Susceptibility-Weighted Imaging at Ultra-High Field (7 T) in the Evaluation of Brain Tumors. World Neurosurg. 2012;77(5-6):654-6.

21- Tsui YK, Tsai FY, Hasso AN, Greensite F, Nguyen BV. Susceptibility-weighted imaging for differential diagnosis of cerebral vascular pathology: A pictorial review. J Neurol Sci. 2009;287(1-2):7-16.

22- Ihn YK, Jung WS, Hwang SS. The value of T2*weighted gradient-echo MRI for the diagnosis of cerebral venoussinusthrombosis.ClinImaging.2013;37(3):446-50. 23- Altinkaya N, Demir S, Alkan 0, Tan M. Diagnostic value of $\mathrm{T} 2 *$-weighted gradient-echo MRI for segmental evaluation in cerebral venous sinus thrombosis. J Clin Imaging. 2015;39(1):15-9.

24- Bousser MG, Crassard I. Cerebral venous thrombosis, pregnancy and oral contraceptives. Thromb Res. 2012;130(Suppl.1):S19-22.

25- Ameri A, Bousser MG. Cerebral venous thrombosis. Neurol Clin. 1992;10(1):87-111.

26- Daif A, Awada A, al-Rajeh S, Abduljabbar M, al Tahan AR, Obeid T, et al. Cerebral venous thrombosis in adults. A study of 40 cases from Saudi Arabia. Stroke. 1995;26(7):1193-5.

27- Leach JL, Fortuna RB, Jones BV, Gaskill-Shipley MF. Imaging of cerebral venous thrombosis: Current techniques, spectrum of fi ndings, and diagnostic pitfalls. Radio Graphics. 2006;26(Suppl.1):S19-41.

28- Leach JL, Strub WM, Gaskill-Shipley MF. Cerebral venous thrombus signal intensity and susceptibility effects on gradient recalled-echo MR imaging. 2007;28(5):940-5.

29- Idbaih A, Boukobza M, Crassard I, Porcher R, Bousser MG, Chabriat H. MRI of clot in cerebral venous thrombosis: High diagnostic value of susceptibilityweighted images. Stroke. 2006;37(4):991-5.
1- Barnett HJ, Hyland HH. Noninfective intracranial venous thrombosis. Brain. 1953;76(1):36-49.

2- Linn J, Brückmann H. Cerebral venous and dural sinus thrombosis*: State-of-the-art imaging. Clin Neuroradiol. 2010;20(1):25-37.

3- Selim M, Fink J, Linfante I, Kumar S, Schlaug G, Caplan LR. Diagnosis of cerebral venous thrombosis with echoplanar T2*-weighted magnetic resonance imaging. Arch Neurol. 2002;59(6):1021-6.

4- Caso V, Agnelli G, Paciaroni M. Handbook on Cerebral Venous Thrombosis. Basel: Karger; 2008.

5- Connor SE, Jarosz JM. Magnetic resonance imaging of cerebral venous sinus thrombosis. Clin Radiol. 2002;57(6):449-61.

6- Kim BS, Do HM, Marks MP. Diagnosis and Management of Cerebral Venous and Sinus Thrombosis. Semin Cerebrovasc Dis Stroke. 2004;4(4):205-16.

7- Sajjad Z. MRI and MRV in cerebral venous thrombosis. J Pak Med Assoc. 2006;56(11):523-6.

8- Eichler F, Krishnamoorthy K, Grant PE. Magnetic resonance imaging evaluation of possible neonatal sinovenous thrombosis. Pediatr Neurol. 2007;37(5):31723.

9- Cao G, Parker DL, Sherrill DS, Du YP. Abbreviated moment-compensated phase encoding. Magn Reson Med. 1995;34(2):179-85.

10- Haacke EM, Reichenbach JR. Susceptibility weighted imaging in MRI : Basic concepts and clinical applications. Canada: Wiley-Blackwell; 2011.

11- Lee BC, Vo KD, Kido DK, Mukherjee P, Reichenbach J, Lin W, et al. MR high-resolution blood oxygenation leveldependent venography of occult (low-flow) vascular lesions. AJNR Am J Neuroradiol. 1999;20(7):1239-42.

12- Reichenbach JR, Haacke EM. High-resolution BOLD venographic imaging: A window into brain functio. NMR Biomed. 2001;14(7-8):453-67.

13- Haacke EM, Xu Y, Cheng YC, Reichenbach JR. Susceptibility weighted imaging (SWI). Magn Reson Med. 2004;52(3):612-8.

14- Sehgal V, Delproposto Z, Haacke EM, Tong KA, Wycliffe N, Kido DK, et al. Clinical applications of neuroimaging with susceptibility- weighted imaging. J Magn Reson Imaging. 2005;22(4):439-50.

15- Matsushita T, Anami D, Arioka T, Inoue S, Kariya Y, Fujimoto M, et al. Basic study of susceptibility-weighted imaging at 1.5T. Acta Med Okayama. 2008;62(3):159-68. 16- Haacke EM, Mittal S, Wu Z, Neelavalli J, Cheng Y-CN. 